NEWS

\title{
Fossil finger points to new human species
}

\section{DNA analysis reveals lost relative from 40,000 years ago.}

In the summer of 2008, Russian researchers dug up a sliver of human finger bone from an isolated Siberian cave. The team stored it away for later testing, assuming that the nondescript fragment came from one of the Neanderthals who left a welter of tools in the cave between 30,000 and 48,000 years ago. Nothing about the bone shard seemed extraordinary.

Its genetic material told another story. When German researchers extracted and sequenced DNA from the fossil, they found that it did not match that of Neanderthals - or of modern humans, which were also living nearby at the time. The genetic data, published online in Nature $^{1}$, reveal that the bone may belong to a previously unrecognized, extinct human species that migrated out of Africa long before our known relatives.

“This really surpassed our hopes," says Svante Pääbo, senior author on the international study and director of evolutionary genetics at the Max Planck Institute for Evolutionary Anthropology in Leipzig, Germany. "I almost could not believe

\section{it. It sounded too fantastic to be true."}

Researchers not involved in the work applauded the findings but cautioned against drawing too many conclusions from a single study. "With the data in hand, you cannot claim the discovery of a new species," says Eske Willerslev, an evolutionary biologist and director of the Centre for GeoGenetics at the University of Copenhagen.

If further work does support the initial conclusions, the discovery would mark the first time that an extinct human relative had been identified by DNA analysis. It would also suggest that ice-age humans were more diverse than had been thought. Since the late nineteenth century, researchers have known that two species of Homo - Neanderthals and modern humans - coexisted during the later part of the last ice age. In 2003, a third species, Homo floresiensis, was discovered on the island of Flores in Indonesia, but there has been no sign of this tiny 'hobbit' elsewhere. The relative identified in Siberia, however, raises the

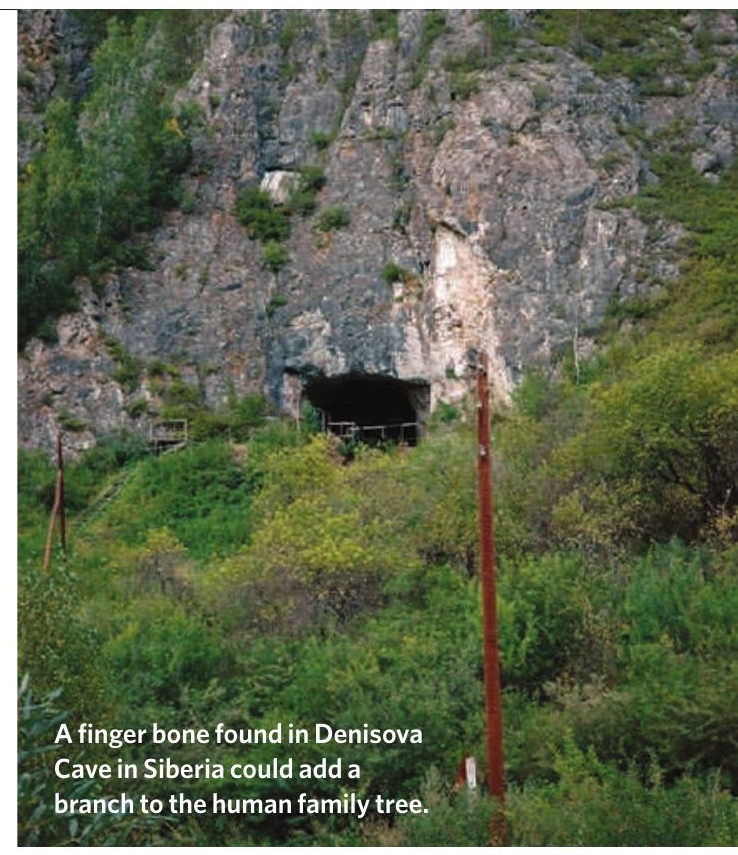

possibility that several Homo species ranged across Europe and Asia, overlapping with the direct ancestors of modern people.

The Siberian site in the Altai Mountains, called Denisova Cave, was already known as a rich source of Mousterian and Levallois artefacts, two styles of tool attributed to Neanderthals. For more than a decade, Russian scientists from the Institute of Archaeology and Ethnology in Novosibirsk have been searching for the toolmakers'

\section{Teams set for first taste of Antarctic lakes}

The pitch-black lakes hidden beneath Antarctica's ice sheet will finally start to release their secrets next year. At a meeting last week, scientists from Russia, the United Kingdom and the United States described their plans to explore the planet's last uncharted ecosystems by drilling into three very different examples of these subglacial lakes.

Over the past 40 years, radar imagery has revealed around 150 freshwater lakes of various sizes and ages beneath the massive Antarctic ice sheet. Some have been isolated from the outside world for millions of years, raising the possibility that they hold unique life forms. The dark, nutrient-deprived environment of the lakes could resemble conditions on Jupiter's moon Europa, which is assumed to hold a large ocean beneath its frozen surface.

Scientists have longed to draw samples from the lakes, but technical problems and environmental concerns have "It's like going fishing in the Everglades, in the Rocky Mountains and in Northern Canada."

able to explore a continental-scale ecosystem that has never before been sampled," says Robin Bell, a senior researcher at Columbia University's Lamont-Doherty
Earth Observatory in Palisades, slowed their progress. Now, the Russian team expects to reach its quarry, Lake Vostok, by February 2011. The Americans and British will follow several years later with forays into lakes with different hydrological and geological characteristics (see graphic).

"Over the next few years we'll be
New York. "This is a madly exciting endeavour."

Lake Vostok is the best known and largest of

the subglacial lakes, measuring roughly the size of Lake Ontario. Buried beneath almost 4,000 metres of ice in eastern Antarctica, the lake is thought to be 35 million years old and could host ancient microbial life.

Russian drillers had planned to penetrate the lake in the 2008-09
Antarctic field season, but their drill got stuck 80 metres above the lake surface. All technical problems have been resolved during the past field season, says Valery Lukin, director of the Russian Antarctic programme, who spoke at the meeting, held by the American Geophysical Union in Baltimore, Maryland.

Some researchers worry that a Russian success could come at the cost of biological and chemical contamination of the pristine waters. "Let's hope they don't spoil the lake," says Robert Bindschadler, a glaciologist at NASA's Goddard Space Flight Center in Greenbelt, Maryland. Lukin says that his country's team has come up with plans to 
bones. They discovered several bone specimens, handling each potentially important new find with gloves to prevent contamination with modern human DNA. The bones' own DNA could then be extracted and analysed.

When the finger bone was discovered, "we didn't pay special attention to it”, says archaeologist Michael Shunkov of the Novosibirsk institute. But Pääbo had established a relationship with the Russian team years before to gather material for genetic testing from ice-age humans. After obtaining the bone, the German team extracted the bone's genetic material and sequenced its mitochondrial DNA (mtDNA) - the most abundant kind of DNA and the best bet for getting an undegraded sequence from ancient tissue.

After re-reading the mtDNA sequences an average of 156 times each to ensure accuracy, the researchers compared them with the mtDNA genomes of 54 modern humans, a 30,000-year-old modern human found in Russia and six Neanderthals. The Denisova Cave DNA fell into a class of its own. Although a Neanderthal mtDNA genome differs from that of Homo sapiens at 202 nucleotide positions on average, the Denisova Cave sample differed at an average of 385 positions.

The differences imply that the Siberian ancestor branched off from the human family tree a million years ago, well before the split between modern humans and Neanderthals. If so, the proposed species must have left Africa in a previously unknown migration, between that of Homo erectus 1.9 million years ago and that of the Neanderthal ancestor Homo heidelbergensis, 300,000 to 500,000 years ago.

Study author Johannes Krause, also at the Max Planck Institute in Leipzig, says that the researchers are now generating nuclear DNA sequences from the bone with the hope of sequencing its entire genome. If they are successful, it would be the oldest human genome sequenced, eclipsing that of the 4,000-year-old Eskimo from Greenland that Willerslev and his colleagues reported last month ${ }^{2}$.

A complete genome might also enable the researchers to give the proposed new species a formal name. They had originally planned to do so on the basis of the mtDNA genome. But they opted to wait until more bones are found - or until the DNA gives a clearer picture of its relationship to modern humans and Neanderthals.

Willerslev emphasizes that, on its own, the mtDNA evidence does not verify that the Siberian find represents a new species because mtDNA is inherited only from the mother. It is possible that some modern humans or Neanderthals living in Siberia 40,000 years ago had unusual mtDNA, which may have come from earlier interbreeding among $H$. erectus, Neanderthals, archaic modern humans or another, unknown species of Homo. Only probes of the nuclear DNA will properly define the position of the Siberian relative in the human family tree.

Anthropologists also want to see morerefined dating of the sediments and a better description of the finger bone itself. "I haven't seen a picture of the bone, and would like to," says Owen Lovejoy, an anthropologist at Kent State University in Ohio. "The stratigraphic age for the bone is 30,000 to 48,000 years old, but the mtDNA age could be as old as H. erectus," says Lovejoy. "That doesn't tell us much about human evolution unless it truly represents a surviving ancient species."

The cave has yielded few clues about the culture of the Siberian hominin, although a fragment of a polished bracelet with a drilled hole was found earlier in the same layer that yielded the bone ${ }^{3}$.

Pääbo suspects that other human ancestors and new mysteries - may emerge as geneticists grind up more ancient bones for sequencing. "It is fascinating that molecular studies make a contribution in palaeontology where there is little or no morphology preserved," he says. "It is clear we stand just in the beginning of many fascinating developments."

Rex Dalton

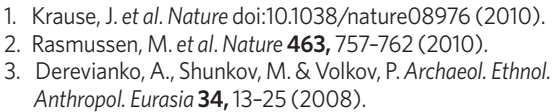

\section{BIZARRE MODELS}

disfigured faces, and yeast hints at blood-vessel growth go.nature.com/p960e9

\section{"I almost could not} believe it. It sounded too true. 